\title{
A novel inlet system for online chemical analysis of semi-volatile submicron particulate matter
}

\author{
P. Eichler ${ }^{1}$, M. Müller ${ }^{1}$, B. D'Anna ${ }^{2}$, and A. Wisthaler ${ }^{1,3}$ \\ ${ }^{1}$ Institut für Ionenphysik und Angewandte Physik, Universität Innsbruck, Innsbruck, Austria \\ ${ }^{2}$ CNRS, UMR5256, IRCELYON, Institut de recherches sur la catalyse et l'environnement de Lyon, Villeurbanne, \\ Université de Lyon, Lyon, 69626, France \\ ${ }^{3}$ Department of Chemistry, University of Oslo, Oslo, Norway
}

Correspondence to: A. Wisthaler (armin.wisthaler@uibk.ac.at)

Received: 28 July 2014 - Published in Atmos. Meas. Tech. Discuss.: 30 September 2014

Revised: 8 February 2015 - Accepted: 25 February 2015 - Published: 20 March 2015

\begin{abstract}
We herein present a novel modular inlet system designed to be coupled to low-pressure gas analyzers for online chemical characterization of semi-volatile submicron particles. The "chemical analysis of aerosol online" (CHARON) inlet consists of a gas-phase denuder for stripping off gasphase analytes, an aerodynamic lens for particle collimation combined with an inertial sampler for the particle-enriched flow and a thermodesorption unit for particle volatilization prior to chemical analysis. The denuder was measured to remove gas-phase organics with an efficiency $>99.999 \%$ and to transmit particles in the $100-750 \mathrm{~nm}$ size range with a 75 $90 \%$ efficiency. The measured average particle enrichment factor in the subsampling flow from the aerodynamic lens was 25.6, which is a factor of 3 lower than the calculated theoretical optimum.

We coupled the CHARON inlet to a proton-transferreaction time-of-flight mass spectrometer (PTR-ToF-MS) which quantitatively detects most organic analytes and ammonia. The combined CHARON-PTR-ToF-MS setup is thus capable of measuring both the organic and the ammonium fraction in submicron particles in real time. Individual organic compounds can be detected down to levels of 10 $20 \mathrm{ng} \mathrm{m}^{-3}$. Two proof-of-principle studies were carried out for demonstrating the analytical power of this new instrumental setup: (i) oxygenated organics and their partitioning between the gas and the particulate phase were observed from the reaction of limonene with ozone and (ii) nicotine was measured in cigarette smoke particles demonstrating that selected organic target compounds can be detected in submicron particles in real time.
\end{abstract}

\section{Introduction}

The characterization of the organic fraction of atmospheric aerosol, which in the following refers to both particles and gases dispersed in air, is still a major analytical challenge. Collection, storage and preparation of atmospheric samples followed by offline analysis are time and labor intensive and often prone to analytical artifacts. This has driven the demand for direct sample introduction or online analytical techniques.

While optical methods are well suited for the online detection of small gas-phase organic molecules (e.g., formaldehyde), chemical ionization mass spectrometry (CI-MS) is the method of choice for detecting more complex organic analytes in an online manner. Online CI-MS techniques for gas-phase organics currently used in atmospheric research include PTR-MS (Hansel et al., 1995), TD-CIMS (Slusher et al., 2004), CIT-CIMS (Crounse et al., 2006) and NI-PTCIMS (Veres et al., 2008).

Particulate organic matter is more difficult to measure online. Currently used online mass spectrometers for particulate organic matter rely on $70 \mathrm{eV}$ electron impact (EI) ionization or photoionization (PI) which both lead to intense fragmentation of most organic analytes (Hoffmann et al., 2011, and references therein). CI is softer but gas-particle separation remains an analytical challenge. This is currently achieved by collecting particles on metal or PTFE surfaces followed by thermal desorption in an inert gas atmosphere and subsequent CI-MS analysis (Voisin et al., 2003; Thornberry et al., 2009; Holzinger et al., 2010; Yatavelli and 
Thornton, 2010; Müller et al., 2012; Aljawhary et al., 2013; Lopez-Hilfiker et al., 2014). Such methods are, however, not truly online and may not avoid surface collection artifacts (see for example Timkovsky et al., 2015). Hellén et al. (2008) developed a true online method suitable for chamber studies with high particle concentrations. A true online CI-MS method for atmospheric particulate organic matter was recently also reported by Vogel et al. (2013).

Herein, we present a novel true online inlet system that

1. efficiently strips off gas-phase analytes,

2. enriches the particle concentration in the analyzer subsampling flow and

3. vaporizes the particles prior to detection with a gasphase analyzer.

We show results from two proof-of-principle studies to demonstrate how the novel inlet can be used for online chemical analysis of sub-micron particles, both primarily emitted and secondarily generated, by PTR-MS.

\section{Experimental}

\subsection{Chemical analysis of aerosol online (CHARON)}

We herein present a novel modular inlet system for online chemical characterization of aerosol, i.e., both gas-phase and particulate-phase organics in air. The "chemical analysis of aerosol online" inlet consists of

1. a gas-phase denuder (GPD) for stripping off gas-phase analytes,

2. an aerodynamic lens (ADL) for particle collimation which is combined with an inertial sampler for the emanating particle-enriched flow,

3. a thermodesorption unit (TDU) for particle volatilization.

The CHARON inlet can, in principle, be used for and adapted to different types of gas-phase analyzers that operate at reduced atmospheric pressure. We coupled it to a proton-transfer-reaction time-of-flight mass spectrometer (PTR-ToF-MS) which quantitatively detects most organic analytes. PTR-ToF-MS also measures ammonia, which means that the CHARON inlet can also be used for analyzing the ammonium fraction in submicron particles. The CHARON inlet is illustrated in Fig. 1.

\subsubsection{Gas-phase denuder}

The gas-phase denuder consists of a NovaCarb F activated charcoal monolith (Mast Carbon International Ltd., Guilford, UK) with a channel density of 210 channels per inch and an open cross section of $36 \%$. The cylindrical denuder (L: $5 \mathrm{~cm}$,
OD: $3 \mathrm{~cm}$ ) is mounted in a stainless steel housing sealed with Viton ${ }^{\circledR}$ O-rings. The flow through the GPD is kept at laminar levels $(755 \mathrm{sccm}, R e=309)$ to minimize particle loss through surface collisions. At the given flow rate, the residence time in the denuder is only about $1 \mathrm{~s}$, which minimizes but does not eliminate volatilization artifacts (Strommen and Kamens, 1999). Such artifacts are not critical for the proofof-principle data shown herein but will need to be quantified in future application studies.

To test the VOC removal efficiency, the GPD was challenged with a certified gas mixture (Apel Riemer Environmental Inc., Broomfield, USA) containing a set of 11 pure and oxygenated hydrocarbons in equimolar concentrations (methanol, acetonitrile, acetaldehyde, acetone, isoprene, methylethylketone, benzene, toluene, xylene, 1,3,5trimethylbenzene, $\alpha$-pinene). Dynamic dilution of the mixture with catalytically $\left(\mathrm{Pt} / \mathrm{Pd}\right.$ at $325^{\circ} \mathrm{C}$ ) cleaned laboratory air resulted in mixing ratios of individual compounds in the 0-30 ppbV range. The total organic load onto the GPD thus ranged from 0 to $330 \mathrm{ppbV}$ during the challenge. A conventional home-built quadrupole PTR-MS instrument was used for measuring VOC concentrations upstream and downstream the GPD.

The particle transmission efficiency of the GPD was tested by feeding it with monodisperse particles in the $20-750 \mathrm{~nm}$ mobility diameter range. Sub-micron particles of different chemical composition were generated from solutions of ammonium nitrate (AN, purity: $\geq 99.0 \%$, Sigma-Aldrich), ammonium sulfate (AS, purity: $\geq 99.0 \%$, Sigma-Aldrich), glutaric acid (GA, purity: $99 \%$, Sigma-Aldrich) and methyl glyoxal ( $\mathrm{MG}, 40 \%$ in $\mathrm{H}_{2} \mathrm{O}$, Sigma-Aldrich), respectively, using a TSI Aerosol Generator 3079 (TSI Inc., Shoreview, USA). The generated particles were dried using a Nafion ${ }^{\circledR}$ dryer (Perma Pure LLC, Toms River, USA) and neutralized using a TSI Soft X-Ray Aerosol Neutralizer 3087. Subsequently, particles were size-selected in the $20-750 \mathrm{~nm}$ size range using a Hauke-type differential mobility analyzer (DMA, built by the Leibniz Institut für Troposphärenforschung e.V., Leipzig, Germany). The resulting monodisperse particles were either passed through the GPD and counted using a TSI 3772 condensation particle counter (CPC; TSI Inc., Shoreview, USA) or directly counted by the CPC.

\subsubsection{Aerodynamic lens}

After passing the GPD, the entire sampling flow enters an aerodynamic lens through a flow-limiting orifice $(300 \mu \mathrm{m})$. ADLs are commonly used to generate focused particle beams and their principle of operation has been described in detail by Liu et al. (1995) and Wang and McMurry (2006). The ADL consists of a relaxation chamber immediately downstream of the critical orifice, four lenses with decreasing diameters, three spacers (outer diameter: $2.54 \mathrm{~cm}$ ) between the lenses and two outlet lines. A coaxial sampling line (outer diameter: $6.35 \mathrm{~mm}$ ) collects the particle-enriched flow on the 


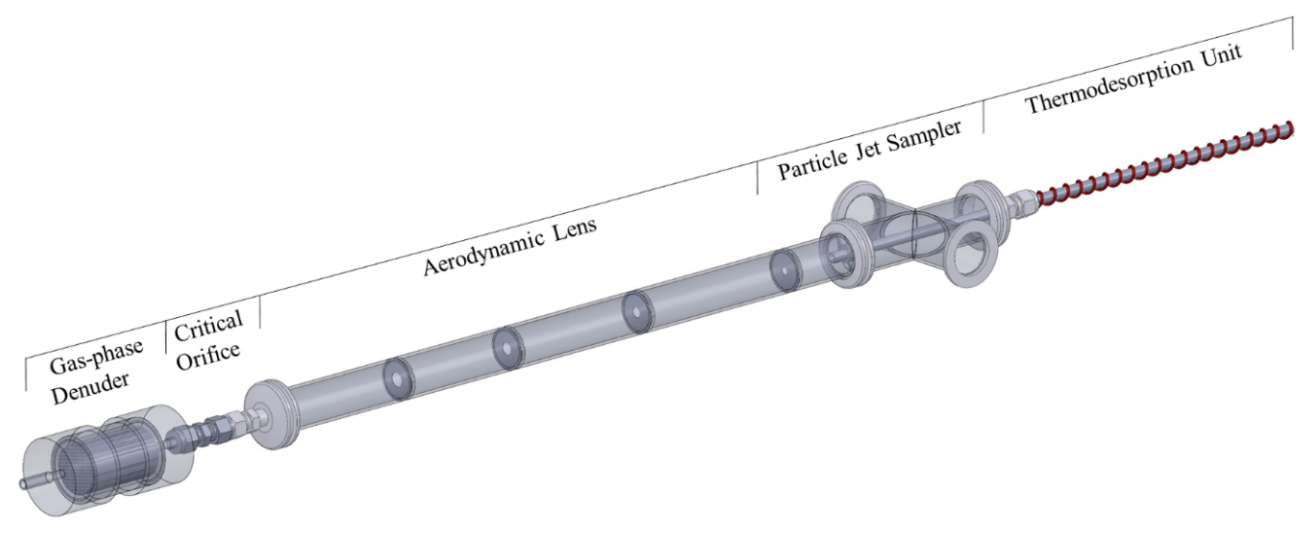

Figure 1. The CHARON inlet with its main components including (i) a gas-phase denuder, (ii) a critical orifice combined with an aerodynamic lens and an inertial sampler for the particle-enriched flow and (iii) a thermodesorption unit.

central axis of the ADL while the remaining gas-phase flow is stripped off laterally using a Varian TriScroll 600 pump (Agilent Inc., Santa Clara, USA). The pressure at the outlet of the ADL is approximately 10 mbar. The maximum achievable enrichment factor is defined by the ratio between the ADL inlet flow $(\sim 755 \mathrm{sccm})$ and the flow in the coaxial outlet sampling line $(\sim 10 \mathrm{sccm})$, which is 75.5 . The Fluent ${ }^{\mathrm{TM}}$ software (ANSYS Inc., Canonsburg, USA) was used for ADL design and optimization.

The particle enrichment factor, i.e., the ratio between the particle mass concentration upstream and downstream of the ADL, was experimentally determined as follows. Particles were generated from AN, AS and dimethylaminium nitrate (DMAN), respectively, using a home-built nebulizer. A buffer vessel was installed downstream of the nebulizer for removing excess water droplets and for increasing signal stability. The sample was subsequently heated to $110^{\circ} \mathrm{C}$ and passed through a Nafion ${ }^{\circledR}$ dryer before being introduced into the GPD. It was then passed through an additional Nafion ${ }^{\circledR}$ dryer to minimize any potential humidity bias in particle mass calculations. Subsequently, particles were size-selected in the $100-750 \mathrm{~nm}$ size range $(50$ $100 \mathrm{~nm}$ scan steps in $2-3$ min intervals) using a neutralizerDMA system (models described in Sect. 2.1.1). The resulting monodisperse particle flow was delivered in parallel to the CPC and to the CHARON inlet. The following input parameters were used to derive the CPC mass concentration: AN (shape factor $=0.8$, density $=1.72 \mathrm{~g} \mathrm{~cm}^{-3}$ ), AS ( shape factor $=0.8$, density $=1.77 \mathrm{~g} \mathrm{~cm}^{-3}$ ), DMAN (shape factor $=1.0$, density $=1.20 \mathrm{~g} \mathrm{~cm}^{-3}$ ). Thermal decomposition of AN, AS and DMAN particles in the CHARON inlet (see Sect. 2.1.3) forms gas-phase ammonia and nitric acid, ammonia and sulfuric acid, and dimethylamine and nitric acid, respectively. The PTR-ToF-MS quantitatively detects ammonia and dimethylamine (see Sect. 2.1.4). The particle enrichment factor was calculated from the ratio between the average PTR-ToF-MS derived mass concentration and the average CPC-derived mass concentration in a given size interval.

\subsubsection{Thermodesorption unit}

A heating wire is used to heat the coaxial outlet sampling line downstream of the ADL to a defined temperature. For the experiments reported herein, we used a temperature of $150^{\circ} \mathrm{C}$ but any temperature between 50 and $250^{\circ} \mathrm{C}$ can be set. The effect of different desorption temperatures will be evaluated in future studies. The heated tube (length: $40 \mathrm{~cm}$, outer diameter: $6.35 \mathrm{~mm}$ ) made of passivated stainless steel (Sulfinert ${ }^{\circledR}$, Restek, Bellefonte, USA) is terminated by a flow-restricting orifice. Particle evaporation occurs in the gas-phase and on tube and orifice surfaces to which submicron particles rapidly diffuse at $10 \mathrm{mbar}$ operating pressure and $150{ }^{\circ} \mathrm{C}$ operating temperature. The TDU was empirically designed based on the criterion that AS particles should be completely vaporized.

\subsubsection{Proton-transfer-reaction time-of-flight mass spectrometer}

A heated passivated stainless steel capillary (length: $30 \mathrm{~cm}$, outer diameter: $3.175 \mathrm{~mm}$, material: Sulfinert ${ }^{\circledR}$ ) was used to couple the CHARON inlet to a recently developed PTR-ToFMS (Müller et al., 2014). The basics of PTR-MS have been described in great detail elsewhere (de Gouw and Warneke, 2007). Sampling gas is continuously flushed through a lowpressure drift cell (2-4 mbar) where externally generated hydronium ions $\left(\mathrm{H}_{3} \mathrm{O}^{+}\right)$unselectively transfer a proton to most organic analytes (except small alkanes and alkenes) and a few inorganic compounds such as ammonia. Protonated analytes are subsequently detected by a quadrupole or time-offlight mass spectrometer. The main advantages of the PTRMS method in the context of aerosol analysis are as follows:

1. PTR-MS detects a broad spectrum of organic molecules including ring-structured pure hydrocarbons and func- 
tionalized hydrocarbons which are important target analytes in the aerosol

2. PTR-MS response factors for different organic analytes typically vary only by $\pm 30 \%$, which allows for a quantitative analysis even without external calibration standard.

The main disadvantages of the PTR-MS method in the context of aerosol analysis are as follows:

1. One-dimensional mass spectrometric analysis, even at high mass resolving power, does not allow to differentiate between isomeric species.

2. Protonation of a functional group (e.g., $-\mathrm{OH}$ or $-\mathrm{ONO}_{2}$ ) often results in the ejection of the respective group (via $\mathrm{H}_{2} \mathrm{O}$ or $\mathrm{HNO}_{3}$ loss, respectively) from the analyte ion, which complicates mass spectral interpretation.

The instrument used for the study presented herein was described in great detail by Müller et al. (2014). It was operated at $E / N=100 \mathrm{Td}$, where $E$ is the electric field strength and $N$ the buffer gas density $\left(1 \mathrm{Td}=10^{-17} \mathrm{~V} \mathrm{~cm}^{2}\right)$. The drift tube was kept at $120^{\circ} \mathrm{C}$. The instrument used has a relatively low mass resolving power $(m / \Delta m \sim 1000)$. Its acetone response factor is $\sim 125 \mathrm{cps} \mathrm{ppbV}^{-1}$. The $2 \sigma$ detection limit of the instrument is in the $50-80 \mathrm{pptV}$ range for $m / z$ signals above $m / z 70$ and a $1 \mathrm{~s}$ signal integration time.

The instrumental response factor for ammonia was determined experimentally in a previous study (Müller et al., 2014). The instrumental response factor for dimethylamine was derived from ion-molecule collision theory following the procedure described by Cappellin et al. (2012).

\subsubsection{Particulate phase, gas-phase and instrument zero measurements}

We used different inlet configurations to measure the particulate phase of the aerosol, the instrumental background and the gas-phase component of the aerosol. The PTR-ToF-MS instrument equipped with the CHARON inlet as shown in Fig. 1 (i.e., including GPD, ADL and TDU) measures the concentration and chemical composition of the particulate phase of the aerosol. The instrumental background is measured by placing a HEPA filter (HEPA-CAP 75; GE Healthcare UK Limited, Buckinghamshire, UK) upstream of the CHARON inlet. The gas-phase component of the aerosol is measured by directly sampling analyte air via a heated passivated stainless steel tube (Sulfinert ${ }^{\circledR}$, Restek, Bellefonte, USA; $T=100^{\circ} \mathrm{C}$, outer diameter: $6.35 \mathrm{~mm}$ ) at a flow rate of several liters per minute. During our initial experiments this tube was capped with a submicron $(0.2 \mu \mathrm{m}$ pore size $)$ PTFE particulate filter. To avoid any potential filter artifacts (e.g., due to off-gassing of semi-volatile compounds) we later used an inertial separator (off-axis subsampling from a highvolume flow; similar to the setup described by Kercher et al., 2009) for particle separation. No evidence for evaporation of residual particles in the heated gas inlet was found. The gas-phase inlet is a completely independent inlet that is connected to the PTR-ToF-MS instrument immediately upstream of the drift tube via a pressure-controlled subsampling PEEK capillary (i.e., the standard inlet used in Ionicon PTRMS instruments). The gas-phase inlet is zeroed by overflowing it with catalytically $\left(\mathrm{Pt} / \mathrm{Pd}\right.$ at $325^{\circ} \mathrm{C}$ ) cleaned sample air. Servo motor activated valves made of passivated stainless steel (Restek, Bellefonte, USA) are used for switching between different inlet configurations. The detailed experimental setup is shown in Fig. S1 in the Supplement.

\subsection{Laboratory experiments}

Two proof-of-principle studies were carried out for demonstrating the analytical potential of our novel instrumental setup. The CHARON inlet was used to sample volatile and semi-volatile species generated from the reaction of limonene with ozone in an indoor environment and to detect nicotine as a specific organic target compound in cigarette smoke particles.

\subsubsection{Characterization of indoor secondary organic aerosol (SOA) from the reaction of ozone with limonene}

Limonene (97\%, Sigma-Aldrich) and ozone were released in a $36 \mathrm{~m}^{3}$ room to generate a particle steady-state mass concentration of $47 \mathrm{\mu g} \mathrm{m}^{-3}$ (single-modal distribution centered at $165 \mathrm{~nm})$. Ozone was generated via a UV lamp flushed with pure oxygen. Particles in room air were monitored with a DMA-CPC system (models described in Sect. 2.1.1). The following input parameters were used to derive the CPC mass concentration: shape factor $=0.8$, density $=0.84 \mathrm{~g} \mathrm{~cm}^{-3}$. Room air was also monitored by PTRToF-MS in the inlet configuration described in Sect. 2.1.5. The PTR-TOF Data Analyzer software was used for data analysis (Müller et al., 2013).

\subsubsection{Detection of nicotine in cigarette smoke particles}

A cigarette was mounted with its filter onto a stainless steel tube and a $65 \mathrm{sccm}$ flow of air was continuously drawn through the cigarette. The outflow was diluted by a factor of 10 with catalytically cleaned $\left(\mathrm{Pt} / \mathrm{Pd}, 325^{\circ} \mathrm{C}\right)$ laboratory air and subsequently fed to the CHARON inlet.

\section{Results}

\subsection{GPD characterization}

\subsubsection{Gas-phase removal efficiency}

The GPD removed 0-30 ppbV levels of gas-phase methanol, acetonitrile, acetaldehyde, acetone, isoprene, methylethylke- 


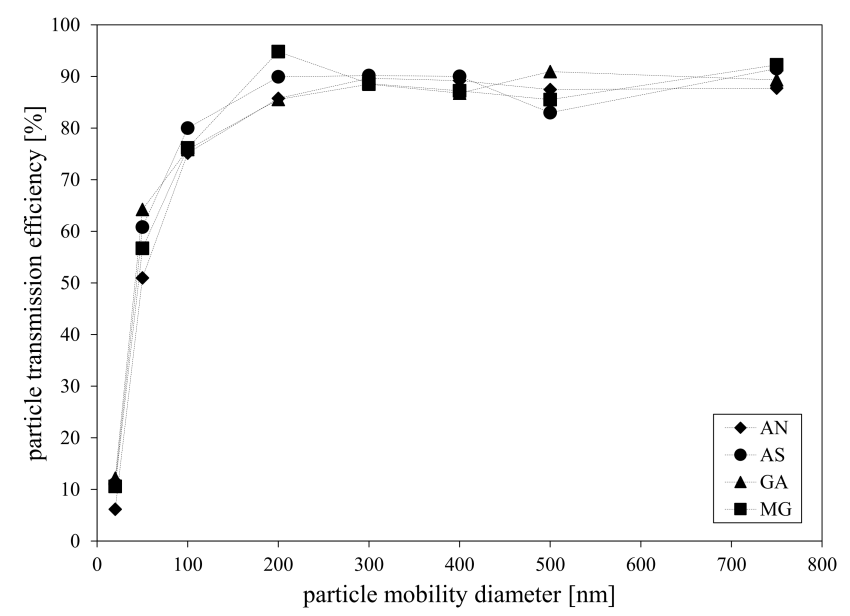

Figure 2. Transmission efficiency of the GPD for size-selected particles generated from ammonium nitrate (AN), ammonium sulfate (AS), glutaric acid (GA) and methyl glyoxal (MG).

tone, benzene, toluene, xylene, 1,3,5-trimethylbenzene and $\alpha$-pinene with an efficiency $>99.999 \%$. During long-term operation, the GPD was regenerated on a monthly basis by baking it at $120^{\circ} \mathrm{C}$ for $8 \mathrm{~h}$ under a stream of catalytically cleaned $\left(\mathrm{Pt} / \mathrm{Pd}, 325^{\circ} \mathrm{C}\right)$ laboratory air. No saturation or breakthrough was observed during 1 month of laboratory operation. We also observed that the GPD efficiently removes gas-phase ammonia at typical indoor levels (single to double digit ppb levels).

\subsubsection{Particle transmission efficiency}

The transmission efficiency of the GPD for size-selected particles generated from AN, AS, GA and MG, respectively, is displayed in Fig. 2. Particles with a mobility diameter of less than $50 \mathrm{~nm}$ are poorly transmitted $(<20 \%)$ as they rapidly diffuse to the GPD surfaces. Particle transmission steeply increases in the $50-100 \mathrm{~nm}$ size range. The transmission efficiency for $100 \mathrm{~nm}$ particles is $75-80 \%$. About $90 \%$ transmission efficiency is achieved for particles in the 200$750 \mathrm{~nm}$ mobility diameter range. The data shown in Fig. 2 suggest that the transmission efficiencies for particles of different chemical composition are very similar. The observed data scatter is mostly caused by variations in the particle load onto the GPD when we sequentially measured upstream and downstream of the device.

\subsection{ADL characterization}

The ADL enrichment factor for AN, AS and DMAN particles in the 200-750 nm size range is shown in Fig. 3. The data collected for particles below $200 \mathrm{~nm}$ were too scattered to report reliable numbers. The average particle enrichment factor calculated from the data shown in Fig. 3 is 25.6, which is a factor of 3 lower than the theoretical optimum. During

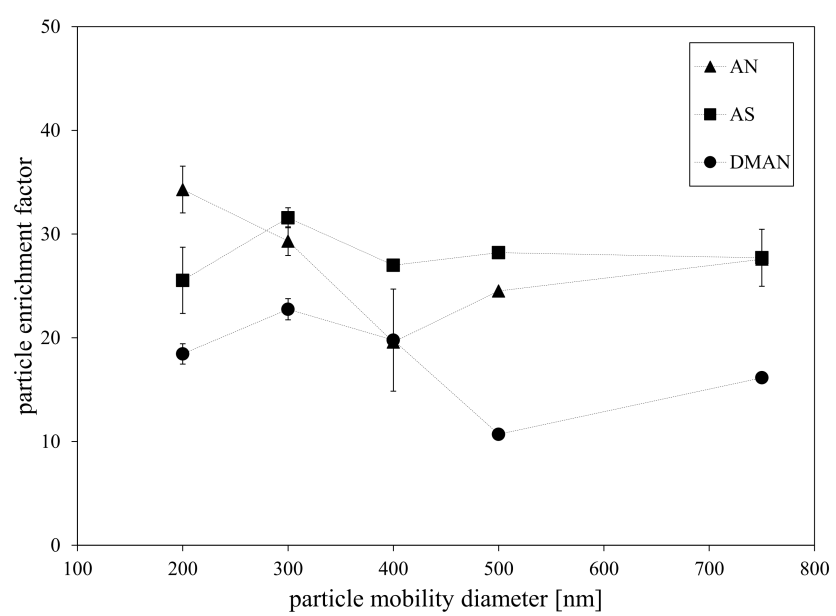

Figure 3. Enrichment factor of the ADL for ammonium nitrate (AN), ammonium sulphate (AS) and dimethylaminium nitrate (DMAN) particles in the $200-750 \mathrm{~nm}$ size range.

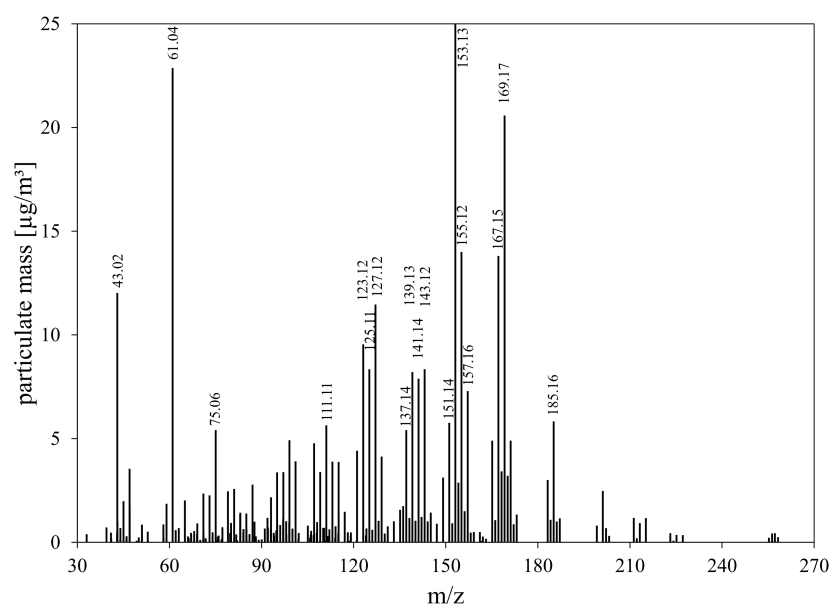

Figure 4. PTR-ToF-MS mass scan obtained from ozone-limonene SOA sampled with the CHARON inlet. Note that the particulate mass is enriched by a factor $\sim 25$.

initial testing we observed an enrichment factor of 73 that, however, degraded over time to reach a stable level of $\sim 25$. This was most likely due to particle deposition at and behind the initial critical orifice. We are currently improving the design of the ADL critical orifice and the relaxation region. The lower DMAN values may be explained by the fact that we used a lower particle drying temperature $\left(80^{\circ} \mathrm{C}\right)(\mathrm{see}$ Sect. 2.1.2) and thus had a larger contribution of water to the particle mass observed by the CPC.

\subsection{Indoor SOA from limonene ozonolysis}

We used the CHARON inlet to sample indoor SOA $\left(22.3 \mu \mathrm{g} \mathrm{m}^{-3}\right.$ above $150 \mathrm{~nm}$ diameter, i.e., where the CHARON inlet works efficiently) generated from the reaction of ozone with limonene. Figure 4 shows the obtained 

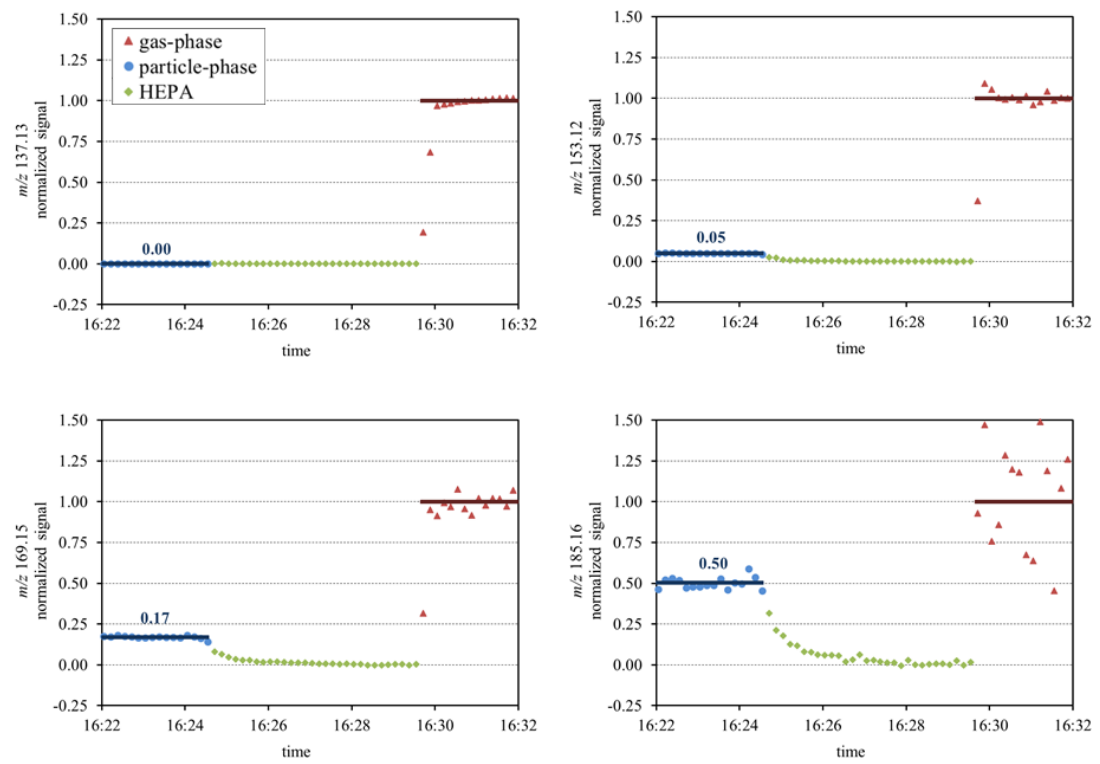

Figure 5. Time traces of the $m / z 137.13\left(\mathrm{C}_{10} \mathrm{H}_{17}^{+}\right), m / z 153.12\left(\mathrm{C}_{10} \mathrm{H}_{17} \mathrm{O}_{1}^{+}\right), m / z 169.15\left(\mathrm{C}_{10} \mathrm{H}_{17} \mathrm{O}_{2}^{+}\right)$and $m / z 185.16\left(\mathrm{C}_{10} \mathrm{H}_{17} \mathrm{O}_{3}^{+}\right)$ signals observed when the particulate phase (in blue), the instrument zero via the HEPA filter (in green) and the gas-phase (in red, signal multiplied with a factor of 25 for direct comparison) were sequentially measured. Signals are normalized to observed average gas-phase levels. The relative fraction of $\mathrm{C}_{10} \mathrm{H}_{17} \mathrm{O}_{1}^{+}, \mathrm{C}_{10} \mathrm{H}_{17} \mathrm{O}_{2}^{+}$and $\mathrm{C}_{10} \mathrm{H}_{17} \mathrm{O}_{3}^{+}$signals detected in the particulate phase increases from 0.05 to 0.17 to 0.50 , respectively, reflecting the increased partitioning of more and more oxygenated species into the particle phase.

PTR-ToF-MS mass scan, which includes $247 \mathrm{~m} / z$ signals in the $m / z 33$ to 250 mass range. All signals were converted into $\mu \mathrm{g} \mathrm{m}^{-3}$ using the observed ionic molecular weight (i.e., loss of neutral fragments was not considered) and using the instrumental response factor for acetone (acetone equivalents). At the current state of knowledge, this should be considered a tentative quantification. The highest signals arise from $\mathrm{C}_{2} \mathrm{H}_{3} \mathrm{O}^{+}\left(m / z\right.$ 43.02) ions, $\mathrm{C}_{2} \mathrm{H}_{5} \mathrm{O}_{2}^{+}(\mathrm{m} / z$ 61.04) ions and $\mathrm{C}_{10} \mathrm{H}_{17} \mathrm{O}^{+}(m / z$ 153.12) ions, the last clearly arising from oxidation of limonene. The lowest detectable signals in the mass spectrum ( $2 \sigma$ above instrumental background) correspond to concentrations of individual organic compounds (in the $m / z$ 125-250 range) on the order of $10-20 \mathrm{ng} \mathrm{m}^{-3}$. At this stage we refrain from making any chemical assignments or giving any further interpretations which we consider to be outside of the scope of this paper. The mass spectrum is shown to demonstrate that the CHARON inlet setup can indeed be used for generating online and real-time PTR-ToFMS mass spectra of SOA at ambient or near-ambient levels.

The total detected mass concentration derived from the observed signals (in acetone equivalents) is $375 \mu \mathrm{g} \mathrm{m}^{-3}$. This converts into a sampled concentration of $17.5 \mu \mathrm{g} \mathrm{m}^{-3}$, assuming an $86 \%$ particle transmission efficiency and a 25 fold particle enrichment for particles larger than $150 \mathrm{~nm}$. Although this is only a rough estimate, the derived mass concentration is in good agreement $(-22 \%)$ with the CPCderived value, confirming that our setup quantitatively detects SOA. Our PTR-ToF-MS analyzer has a relatively low mass resolving power and sensitivity. A high-sensitivity and

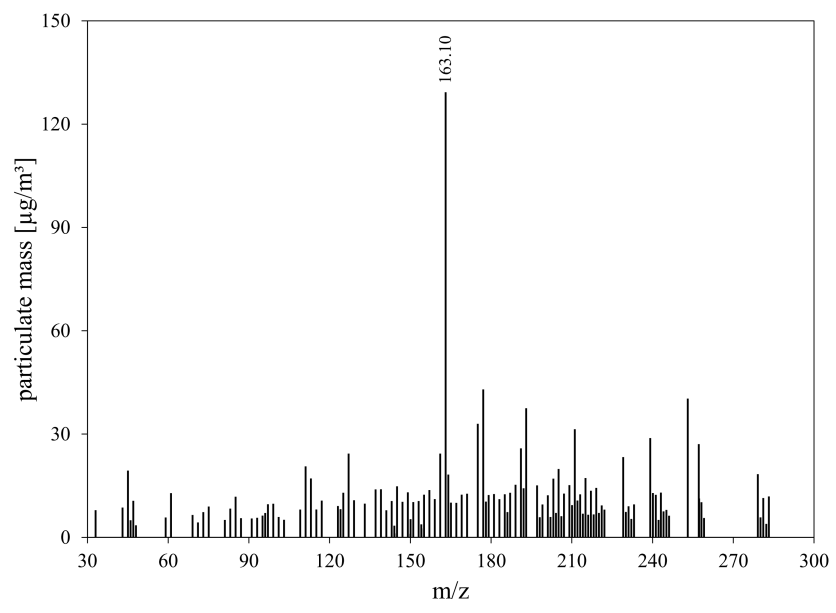

Figure 6. PTR-ToF-MS mass scan obtained when 10-fold diluted cigarette smoke was sampled through the CHARON inlet. The prominent peak at $m / z 163.12\left(\mathrm{C}_{10} \mathrm{H}_{14} \mathrm{~N}_{2}^{+}\right)$corresponds to protonated nicotine. Note that the particulate mass is enriched by a factor $\sim 25$.

high-mass-resolution PTR-ToF-MS instrument coupled to a CHARON inlet will generate abundant quasi-molecular ion signals combined with highly accurate $m / z$ information. This will generate valuable data sets for improving elemental (e.g., $\mathrm{O}: \mathrm{C}$ ratio) and chemometric analyses.

We also used the inlet setup as shown in Fig. S1 to measure both the particulate and the gas-phase component of 
the aerosol. Figure 5 shows the time traces of limonene $\left(\mathrm{C}_{10} \mathrm{H}_{17}^{+}\right)$detected at $m / z 137.13$ (upper left panel) and the three limonene oxidation products $\mathrm{C}_{10} \mathrm{H}_{17} \mathrm{O}_{1}^{+}$(upper right panel), $\mathrm{C}_{10} \mathrm{H}_{17} \mathrm{O}_{2}^{+}$(lower left panel) and $\mathrm{C}_{10} \mathrm{H}_{17} \mathrm{O}_{3}^{+}$(lower right panel) detected $m / z 153.12,169.15$ and 185.16 , respectively.

The mass axis was not calibrated above $m / z$ 137.13, which explains the relatively poor mass accuracy of high $\mathrm{m} / z$ signals. All signals were normalized to average signal levels detected in the gas phase (data in red). Particle-phase measurements via the CHARON inlet were conducted in the period from 16:21:00 to 16:24:45 LT (data shown in blue), after which a HEPA-filter was switched in-line upstream of the CHARON setup (data in green). All signals decayed to background levels within 2 min. At 16:29:45 the gas-phase inlet was activated (data in red). To make the gas-phase signals directly comparable to the particle-phase signals, we multiplied them with an enrichment factor of 25 . As expected, limonene is exclusively observed in the gas phase. The relative fraction of the particulate-phase signal increases from 0.05 to 0.17 to 0.50 for the $\mathrm{C}_{10} \mathrm{H}_{17} \mathrm{O}_{1}^{+}, \mathrm{C}_{10} \mathrm{H}_{17} \mathrm{O}_{2}^{+}$ and $\mathrm{C}_{10} \mathrm{H}_{17} \mathrm{O}_{3}^{+}$ions, respectively. We interpret these observations as an increased partitioning of more and more oxygenated species into the particle phase. The higher noise in the gas-phase $\mathrm{C}_{10} \mathrm{H}_{17} \mathrm{O}_{3}^{+}$signal is caused by low signal intensities which are multiplied by a factor of 25 . We again refrain from going into further details or analyses. Figure 5 is shown to demonstrate the analytical potential of our novel instrumentation to study the partitioning of organic compounds between the gas and the particulate phase. Further studies are warranted to characterize potential artifacts from inlet and instrumental surfaces.

\subsection{Nicotine detection in cigarette smoke particles}

In another proof-of-principle study we used the CHARON inlet to sample 10-fold diluted cigarette smoke. Figure 6 shows the obtained PTR-ToF-MS mass scan with a prominent peak at $m / z 163.12\left(\mathrm{C}_{10} \mathrm{H}_{14} \mathrm{~N}_{2}^{+}\right)$corresponding to protonated nicotine. While it obviously still remains a challenge to assign the plethora of peaks in the mass spectrum to specific analytes, these data prove that the CHARON-PTR-ToFMS setup can be used to detect and monitor specific organic target compounds in submicron particles in real time. It is a major advantage over existing EI-based or PI-based aerosol mass spectrometry techniques that abundant quasi-molecular ion signals, $[\mathrm{M}+\mathrm{H}]^{+}$, are generated from organic target analytes. In combination with a high-sensitivity PTR-QiTOF instrument (Sulzer et al., 2014), perhaps in the future even with MS-MS capability, our CHARON inlet will allow for highly sensitive and specific detection of organic target compounds in submicron particles in real time.

\section{Conclusions and outlook}

We have shown how our novel CHARON inlet efficiently strips off gas-phase analytes ( $>99.999 \%$ ), enriches the particle concentration by a factor of 25 and subsequently vaporizes the particles for analysis by PTR-ToF-MS. We have demonstrated in two proof-of-principle studies that the novel inlet can be used for true online analysis of particles, both primarily emitted and secondarily generated, in the 150$1000 \mathrm{~nm}$ size range. A potential future application is the study of the partitioning of organic compounds between the gas and the particulate phase. We have also shown that PTRToF-MS analysis generates abundant quasi-molecular ions from organic analytes. Individual compound identification will still remain a challenge but chemometrics, elemental analysis (e.g., $\mathrm{O}: \mathrm{C}$ ratio) and tracer detection will strongly benefit from our new experimental approach. We are currently developing a new CHARON prototype with a 2-3fold improved particle transmission efficiency. Coupling to a high-sensitivity high-mass-resolution PTR-TOF instrument will result in an even more powerful instrument for online particle analysis.

\section{The Supplement related to this article is available online at doi:10.5194/amt-8-1353-2015-supplement.}

Acknowledgements. We thank Simon Kasseroler for machining parts of the CHARON inlet. This work is funded through the PIMMS ITN, which is supported by the European Commission's 7th Framework Programme under grant agreement number 287382. The PTR-ToF-MS instrument used for this study was funded through the Austrian Space Applications Programme (ASAP 8, \#833451). ASAP is sponsored by the Austrian Ministry for Transport, Innovation and Technology (BMVIT) and administered by the Aeronautics and Space Agency (ALR) of the Austrian Research Promotion Agency (FFG).

Edited by: G. Phillips

\section{References}

Aljawhary, D., Lee, A. K. Y., and Abbatt, J. P. D.: High-resolution chemical ionization mass spectrometry (ToF-CIMS): application to study SOA composition and processing, Atmos. Meas. Tech., 6, 3211-3224, doi:10.5194/amt-6-3211-2013, 2013.

Cappellin, L., Karl, T., Probst, M., Ismailova, O., Winkler, P. M., Soukoulis, C., Aprea, E., Märk, T. D., Gasperi, F., and Biasioli, F.: On Quantitative Determination of Volatile Organic Compound Concentrations Using Proton Transfer Reaction Time-ofFlight Mass Spectrometry, Environ. Sci. Technol., 46, 2283 2290, doi:10.1021/es203985t, 2012. 
Crounse, J. D., McKinney, K. A., Kwan, A. J., and Wennberg, P. O.: Measurement of Gas-Phase Hydroperoxides by Chemical Ionization Mass Spectrometry, Anal. Chem., 78, 6726-6732, doi:10.1021/ac0604235, 2006.

De Gouw, J. and Warneke, C.: Measurements of volatile organic compounds in the earth's atmosphere using proton-transferreaction mass spectrometry, Mass Spectrom. Rev., 26, 223-257, doi:10.1002/mas.20119, 2007.

Hansel, A., Jordan, A., Holzinger, R., Prazeller, P., Vogel, W., and Lindinger, W.: Proton transfer reaction mass spectrometry: online trace gas analysis at the ppb level, Int. J. Mass Spectrom., 149-150, 609-619, doi:10.1016/0168-1176(95)04294-U, 1995.

Hellén, H., Dommen, J., Metzger, A., Gascho, A., Duplissy, J., Tritscher, T., Prevot, A. S. H., and Baltensperger, U.: Using Proton Transfer Reaction Mass Spectrometry for Online Analysis of Secondary Organic Aerosols, Environ. Sci. Technol., 42, 73477353, doi:10.1021/es801279m, 2008.

Hoffmann, T., Huang, R.-J. and Kalberer, M.: Atmospheric Analytical Chemistry, Anal. Chem., 83, 4649-4664, doi:10.1021/ac2010718, 2011.

Holzinger, R., Kasper-Giebl, A., Staudinger, M., Schauer, G., and Röckmann, T.: Analysis of the chemical composition of organic aerosol at the Mt. Sonnblick observatory using a novel high mass resolution thermal-desorption proton-transfer-reaction mass-spectrometer (hr-TD-PTR-MS), Atmos. Chem. Phys., 10, 10111-10128, doi:10.5194/acp-10-10111-2010, 2010.

Kercher, J. P., Riedel, T. P., and Thornton, J. A.: Chlorine activation by $\mathrm{N}_{2} \mathrm{O}_{5}$ : simultaneous, in situ detection of $\mathrm{ClNO}_{2}$ and $\mathrm{N}_{2} \mathrm{O}_{5}$ by chemical ionization mass spectrometry, Atmos. Meas. Tech., 2, 193-204, doi:10.5194/amt-2-193-2009, 2009.

Liu, P., Ziemann, P. J., Kittelson, D. B., and McMurry, P. H.: Generating Particle Beams of Controlled Dimensions and Divergence: II. Experimental Evaluation of Particle Motion in Aerodynamic Lenses and Nozzle Expansions, Aerosol Sci. Tech., 22, 314-324, doi:10.1080/02786829408959749, 1995.

Lopez-Hilfiker, F. D., Mohr, C., Ehn, M., Rubach, F., Kleist, E., Wildt, J., Mentel, Th. F., Lutz, A., Hallquist, M., Worsnop, D., and Thornton, J. A.: A novel method for online analysis of gas and particle composition: description and evaluation of a Filter Inlet for Gases and AEROsols (FIGAERO), Atmos. Meas. Tech., 7, 983-1001, doi:10.5194/amt-7-983-2014, 2014.

Müller, M., Graus, M., Wisthaler, A., Hansel, A., Metzger, A., Dommen, J., and Baltensperger, U.: Analysis of high mass resolution PTR-TOF mass spectra from 1,3,5-trimethylbenzene (TMB) environmental chamber experiments, Atmos. Chem. Phys., 12, 829-843, doi:10.5194/acp-12-829-2012, 2012.

Müller, M., Mikoviny, T., Jud, W., D’Anna, B., and Wisthaler, A.: A new software tool for the analysis of high resolution PTR-TOF mass spectra, Chemometr. Intell. Lab., 127, 158-165, doi:10.1016/j.chemolab.2013.06.011, 2013.

Müller, M., Mikoviny, T., Feil, S., Haidacher, S., Hanel, G., Hartungen, E., Jordan, A., Märk, L., Mutschlechner, P., Schottkowsky, R., Sulzer, P., Crawford, J. H., and Wisthaler, A.: A compact PTR-ToF-MS instrument for airborne measurements of volatile organic compounds at high spatiotemporal resolution, Atmos. Meas. Tech., 7, 3763-3772, doi:10.5194/amt-7-37632014, 2014.
Slusher, D. L., Huey, L. G., Tanner, D. J., Flocke, F. M., and Roberts, J. M.: A thermal dissociation-chemical ionization mass spectrometry (TD-CIMS) technique for the simultaneous measurement of peroxyacyl nitrates and dinitrogen pentoxide, J. Geophys. Res., 109, D19315, doi:10.1029/2004JD004670, 2004.

Strommen, M. R. and Kamens, R. K.: Simulation of Semivolatile Organic Compound Microtransport at Different Time Scales in Airborne Diesel Soot Particles, Environ. Sci. Technol., 33, 17381746, doi:10.1021/es981035q, 1999.

Sulzer, P., Hartungen, E., Hanel, G., Feil, S., Winkler, K., Mutschlechner, P., Haidacher, S., Schottkowsky, R., Gunsch, D., Seehauser, H., Striednig, M., Jürschik, S., Breiev, K., Lanza, M., Herbig, J., Märk, L., Märk, T. D., and Jordan, A.: A Proton Transfer Reaction-Quadrupole interface TimeOf-Flight Mass Spectrometer (PTR-QiTOF): High speed due to extreme sensitivity, Int. J. Mass Spectrom., 368, 1-5, doi:10.1016/j.ijms.2014.05.004, 2014.

Thornberry, T., Murphy, D. M., Thomson, D. S., de Gouw, J., Warneke, C., Bates, T. S., Quinn, P. K., and Coffman, D.: Measurement of Aerosol Organic Compounds Using a Novel Collection/Thermal-Desorption PTR-ITMS Instrument, Aerosol Sci. Tech., 43, 486-501, doi:10.1080/02786820902763132, 2009.

Timkovsky, J., Dusek, U., Henzing, J. S., Kuipers, T. L., Röckmann, T., and Holzinger, R.: Offline thermal-desorption proton-transfer-reaction mass spectrometry to study composition of organic aerosol, J. Aerosol Sci., 79, 1-14, doi:10.1016/j.jaerosci.2014.08.010, 2015.

Veres, P., Roberts, J. M., Warneke, C., Welsh-Bon, D., Zahniser, M., Herndon, S., Fall, R., and de Gouw, J.: Development of negative-ion proton-transfer chemical-ionization mass spectrometry (NI-PT-CIMS) for the measurement of gas-phase organic acids in the atmosphere, Int. J. Mass Spectrom., 274, 48-55, doi:10.1016/j.ijms.2008.04.032, 2008.

Vogel, A. L., Äijälä, M., Brüggemann, M., Ehn, M., Junninen, H., Petäjä, T., Worsnop, D. R., Kulmala, M., Williams, J., and Hoffmann, T.: Online atmospheric pressure chemical ionization ion trap mass spectrometry (APCI-IT-MSn) for measuring organic acids in concentrated bulk aerosol - a laboratory and field study, Atmos. Meas. Tech., 6, 431-443, doi:10.5194/amt-6-431-2013, 2013.

Voisin, D., Smith, J. N., Sakurai, H., McMurry, P. H., and Eisele, F. L.: Thermal Desorption Chemical Ionization Mass Spectrometer for Ultrafine Particle Chemical Composition, Aerosol Sci. Tech., 37, 471-475, doi:10.1080/02786820300959, 2003.

Wang, X. and McMurry, P. H.: A Design Tool for Aerodynamic Lens Systems, Aerosol Sci. Tech., 40, 320-334, doi:10.1080/02786820600615063, 2006.

Yatavelli, R. L. N. and Thornton, J. A.: Particulate Organic Matter Detection Using a Micro-Orifice Volatilization Impactor Coupled to a Chemical Ionization Mass Spectrometer (MOVI-CIMS), Aerosol Sci. Tech., 44, 61-74, doi:10.1080/02786820903380233, 2010. 